\title{
Challenges for New Teachers and Ways of Coping with Them
}

\author{
Samantha L. Dias-Lacy ${ }^{1} \&$ Ruth V. Guirguis ${ }^{2}$ \\ ${ }^{1}$ School of Education, Hofstra University, Long Island, NY, USA \\ ${ }^{2}$ School of Education, Pace University, NY, NY, USA \\ Correspondence: Ruth V. Guirguis, School of Education, 163 Williams St., NY, NY, 10038, USA. Tel: \\ 1-516-521-3061.E-mail: rguirguis@pace.edu
}

Received: March 26, 2017

Accepted: April 12, 2017

Online Published: May 4, 2017

doi:10.5539/jel.v6n3p265

URL: http://doi.org/10.5539/jel.v6n3p265

\begin{abstract}
The first year of a teacher's career can determine their longevity within the field of education. The issues of first year teachers were analyzed through a grounded theory qualitative research analysis. The results of this study indicate that a first year teacher may feel stress, lack appropriate support, and may feel unprepared to handle behavioral and academic issues among their students. Based on the literature review, the implementation of mentoring programs between new and experienced teachers not only benefited novice teachers but guided them to cope and face the anxieties during the first year in the classroom. Further implications are presented in the regarding some mentoring programs and the impact for first year teachers when not implemented due to limited funding and/or lack of administrative support.
\end{abstract}

Keywords: stress, attrition, coping, teaching practice, first year teacher

\section{Introduction}

\subsection{Introduction}

Entering the field of education with unrealistic expectations of what teaching is about can yield negative experiences for new educators. For the purposes of this research analysis, a first year teacher will refer to an individual who entered the field of education and is teaching for the very first time in their career. As such the inexperience of a first year teacher leads to high level of stress. Based on the literature, first year teachers leave the field of education due to the lack of administrative support, inability to manage personal and professional expectations, limited teaching resources, lack of professional development, and difficulty handling behavioral problems in the classroom. There is an increased rate of attrition by as much as $50 \%$ of teachers leave teaching within the first three to five years (Le Maistre \& Paré, 2008). The current state of first year teachers also referred to as novice teachers, choosing to leave the field at such high rates has provoked administrators to devise a number of coping mechanisms. These mechanisms can be utilized by teachers as they begin their careers in the field of education. The concern of attrition, and lack of coping mechanisms is apparent in a specific sub-section within the education field. Specifically, in high needs geographical areas and in high needs subjects.

\subsection{Current Trend}

According to Darling-Hammond, Furger, Shields, and Sutcher (2016) attrition does have variations specifically with regards to teacher preparation. The less preparation a teacher has received prior to entering the field, the more likely this will lead to a rate of two to three times as high of attrition than with candidates who finished their preparation program before teaching. There is also an increased attrition rate in high-poverty, high-minority schools. Students that attend a high-poverty, high-minority school, tend to be taught by teachers who are underprepared, inexperienced, or teaching outside their licensed area (Darling-Hammond, 2010). The credential issues of underprepared teachers by the Education Department has increased from just 98 in 2010-2011 to more than 900 by 2015-2016 (Nix, 2015). Thus, struggling teachers when unsupported leave teaching. Specially, as $82 \%$ of special educators across the nation state that there is lack of support when trying to meet the needs of students with disabilities (Hale, 2015). Consequently, $51 \%$ of school districts and $90 \%$ of actual schools, report having difficulty recruiting highly qualified special education teachers (Hale, 2015). 


\subsection{Can Learning to Cope Reduce Attrition?}

Coping is perceived as an integral part of a process in which the human organism adapts to his or her living environment (Yiu-Chung Ko et al., 2000). Ko et al. (2000) determined that these coping aspects and stress behaviors often serve the purpose of expressing and/or communicating that a novice educator is under stress; as well enabling teachers to respond to the stressful situations in the work field. Offering a myriad of mechanisms to new teachers may help and support them to better assimilate to their new school cultures and roles. Implementation of these mechanisms have proven to be approaches, which significantly reduced the number of first year teachers who experienced frustration, unrewarding and intolerable difficulty throughout the school year, and desire or decided to leave the profession. Various literature exposed that those who do not find a coping mechanism ultimately increase the risk of becoming an overwhelmed educator with responsibilities that while are part of the educational field can not be properly dealt with (Fantilli \& McDougall, 2005). In addition to the lack of support reported by first year teachers, another reason for high attrition rates among beginning teachers is the difference between expectations in the job of novice teachers versus what the training programs exposed each teacher to prior to graduation (Le Maistre \& Paré, 2009).

\subsection{Literature Review and Research Questions}

The review of the literature revealed that first year teachers experience stress and other professional related difficulties. The majority of the literature favored the implementation of a mentoring and/or induction programs for first year teachers.

\subsubsection{Collaborative Thoughts on Mentoring Programs}

It is imperative to amend the attrition rates within new teachers in the field. One way to ameliorate this problem is through the implementation of mentoring programs. Le Maistre and Paré (2009) explaines that when programs resembling a mentoring and/or induction programs can serve as the bridge between those who are in need of gaining knowledge and those who are certified in various areas with expertise. A mentoring program allows a first year teacher to work with an experienced teacher to improve upon their techniques and pedagogical approaches. A new teacher is also able to develop a personal relationship with a more experienced educator; they are able to share emotions and experiences with one another. An induction program aims to facilitate and increase teaching effectiveness of new teachers through the expertise of veteran teachers (Moir, 2009; Goldrick, 2016). A mentor is experienced and is able to share a plethora of thoughts and ideas related to education. There are a number of benefits of mentoring programs for new teachers, these benefits include: higher retention rates; considerable professional development, improved ability to problem solve in the classroom, adoption of strategies and practice techniques from their mentors, higher confidence and self-esteem, decreased sense of isolation, and an overall improved attitude towards teaching (Fantilli \& Mc Dougall, 2009; Sun, 2012). Despite the implementation of a mentoring program few state policies meet common key aspects that would make mentoring programs high-quality programs (Goldrick, 2016).

Utilizing mentoring programs might have been a solution to not only high attrition rates, but also assisted first year teachers with their ability to cope with work overload, stress, and lack of support from superiors. Darling-Hammond (2006) expressed, the need to enter the field already knowing how and when to implement a variety of teaching practices to accomplish learning goals and meet set Common Core Standards. A novice teacher has to be able to multitask and cope with a myriad of dilemmas that take place in the classroom with all students (Darling-Hammond, Furger, Shields, \& Sutcher, 2016). First year teachers throughout the review of the literature, primarily stated the amount of stress they endeavored on a daily basis. A quantitative and qualitative analysis of stress and coping of teachers revealed, work overload and paperwork in the special education field to be the most stressful (Ko et al., 2000; Goldrick, 2016). While stress comes to all educators in the field with curriculum changes and/or policy changes, new teachers have a greater difficulty handling such stress. The adjustment of transitioning from a teacher candidate to teacher a can be rather overwhelming. Another source of stress reported is caused by the lack of support directly from administrators. The participant in this case study experienced similar sources of stress during the first year of teaching. The participants noted feelings of disappointment when turning to her director for advice on how to teach her course. Particularly, in the way the director responded to with statements of not being able to help but also suggesting changing the textbook so the participant would better understand the material alone. Responses such as these make new teachers feel underappreciated and disappointed in the leadership of schools. 


\subsubsection{Measures Taken by Preparation Programs}

Teacher programs have also tried to better prepare educators by establishing a set amount of hours that must be completed in student teaching. Through student teaching many soon to be teachers, have the opportunity to experience what it is like to be in a classroom. However, when demonstrating a lesson through these internship programs, student teachers do not have the opportunity to experience first hand any discipline problems or curriculum issues. Additionally, they come to a misleading conclusion that they are able to handle the stress and challenges that occur during the first year of teaching. Performance assessment and portfolio evaluations are important features also introduced in support of new teachers by preparation programs (Darling-Hammond, 2006; Darling-Hammond et al., 2016). Offering these assessments can offer higher level of support by allowing teacher candidates to engage in and analyze the products of teaching and learning in useful ways (Everhart \& Hogarty, 2009).

\subsubsection{Opposing Views on Various Coping Mechanisms}

Although school districts and teacher preparation programs agree that through some degree of mentoring or induction program, the attrition rate among novice teachers can reduce significantly (Fantilli \& McDougall, 2005). Attrition rates are still high and many novice teachers still have to cope with the lack of support that exists in many schools. Since many schools tend to implement their own type of an induction program, there exist very large variations among different schools specifically in the types of induction programs that are set and offered to beginning teachers (Smith \& Ingersoll, 2004). These variations are apparent in several schools, which have been closely associated with the high turnover rates of beginning teachers (Smith \& Ingersoll, 2004). The results from Smith and Ingersoll's (2004) quantitative research indicated and supported that when new teachers participated in a well constructed type of induction program with accountability on the mentoring teacher, and where the mentoring teachers assisted newer teachers of the same subject and had common planning time, these programs and thus, reduced the stress factors in new teachers.

In addition to teacher preparation programs, some researchers argued that instead of implementing mentoring programs a buddy programs should be put into practice. Buddy programs are cost effective to the school districts that decide to use them. Having a buddy teacher that is willing to guide new teachers can be successful if the buddy teacher is efficient at listening to new years (Hamlin \& Hering, 1988). Even if a principal appoints a buddy teacher, the only training they would need is to review the school procedures and policies, resources, and have a working knowledge of the most common issues experienced by first year teachers (Hamlin \& Hering, 1988).

\subsubsection{Further Inquiry and Exploration}

Research has yet to be conducted on how the lack of having common standards in how an induction program should be structured, which allows for variability in the type of support from these programs, can reduce the ratio of 3 in 10 teachers moving to a different school or leave the teaching profession once they have completed their first year (Smith \& Ingersoll, 2004).

In addition to defining mentoring and induction programs, further exploration needs to go into ways schools can receive proper funding to implement these programs. When a teacher preparation program is properly funded, it can be very successful. As in other countries, where there is more funding allocated to mentoring programs, in the United States, school districts have little funding for such programs leading to the concerning amount of teachers parting from the field. While many programs are intensifying to prepare more effective teachers, there are limited systemic policy supports for subsidies and programmatic funding that other countries receive (Darling-Hammond, 2006; Darling-Hammond, 2016). Teachers would be able to receive proper training and would be able to cope with the difficulties of the first year of teaching. Hamling and Hering (1988) pointed out "the financial reality is that few districts can afford to provide a trained cadre of instructional mentors in each school building and provide each of these mentors release time" (p. 126).

Research Question: What mechanisms can better support novice teachers during their first years in teaching?

Research Question: What strategies can higher teacher education programs implement to support recently graduated teachers?

\section{Method}

Ko et al. (2000) used a quantitative and qualitative approach to their research. They surveyed a number of educators and were able to use the data they gathered to determine the various coping mechanisms used by educators in the field. Other researchers such as Fantilli and McDougall (2009) used a more mixed methods 
approach and also performed individual case studies on various educators while Smith and Ingersoll (2004) strictly used a quantitative approach in the study of turnover and induction programs. The majority of the research within the literature review was primarily based upon qualitative approaches in order to identify and understand various coping mechanisms.

\subsection{Methodological Approach}

In order to explain and identify the core development in the experiences of a first year teacher, a grounded theory qualitative research analysis was conducted. Grounded theory was chosen since it is more inductive than content analysis, and the theory for this study emerged from the entries analyzed. This approach was taken in order to reduce the probability of missing and/or disregarding relevant information within each diary entry of the participant.

\subsection{Participant (Subject) Characteristics}

This single subject study consisted of a compilation of a school year's worth of diary entries from a first year Spanish high school teacher from Chicago, Illinois. At the time that the diary entries were posted, she was near completing a Masters in Education from a very good program. Additionally, she has not only taken Spanish early on in her elementary school career, but has immersed herself in the language and culture by living in a Spanish speaking country. She embarked on her teaching career in August of 2008.

\subsection{Research Design}

In theoretical sampling, the researchers had an important role in intricately coding and analyzing each diary entry to develop the coping mechanism for first year teachers' theory. Constant questioning and meticulous observation led to the development of this theory. Each diary entry was "disassembled" by paragraph and through micro, open, and axial coding, rearranged once again into manageable chunks that facilitated an understanding of the relationship between the core phenomenon; coping mechanisms.

The process involved constant comparison between the raw data in the diary entries and developing concepts and categories. The analytical process took place in several different stages, beginning with the micro coding of the diary entries. The language expressed in the diary entries determined the micro coding used; in many cases the language was very "conceptually expressive" that they were coded through the use of "In-Vivo" coding. These descriptors allowed for the data to take on more meaning and facilitated the process of documentation and in the arrangement of clustering common concepts such as high sense of responsibility, concern for students, planfulness/preparation, concern to be an effective teacher, and job/role satisfaction (see Figure 1).

Subsequently, the data was analyzed using open and axial coding. At the same time, during the process of qualifying the properties and dimensions of the sources of frustration and coping mechanisms developed by new teacher, memoing was heavily engaged. The use of memos, which occurred with every journal entry and throughout the analytical process of each entry, in this study assisted with the formulation of the theory. Finally, a theory emerged and it was used as a foundation for further analytical research.

\section{Results}

"In three weeks I start a new job as a high school Spanish teacher, and I'm ready. I'm so ready...but I am having trouble sleeping" (August 2008). Several emotions, frustrations, and challenges faced by first year teachers emerged from the data collected in the diary entries. During the first entry, a very positively anxious teacher presented her enthusiasm and eagerness to get into the classroom and teach. From the data, once she gets into the classroom different challenges began to emerge. These challenges were lack of support, time management and curriculum adjustments, discipline issues, and the sense of being overwhelmed (see Table 1).

Table 1. Major sources of stress and coping mechanism

\begin{tabular}{ll}
\hline Sources & Mechanisms \\
\hline Work overload & Seek administrative support \\
Lack of support from teachers & Seeks outside sources of support \\
Lack of support from administration & Re-evaluation of teaching \\
Discipline challenges & Accept situation \\
Curriculum challenges & Seek within school support \\
\hline
\end{tabular}




\begin{tabular}{ll}
\hline Work demands and family demands & Time Management \\
Wanting to meet self expectations & Re-evaluation of teaching \\
Lack of set routines & Seek staff and administrative support \\
Classroom time management & Mentor support \\
Not having clear expectation & Mentor/Buddy teacher support
\end{tabular}

Note. Table 1 summarizes the major sources leading to stress for the participant during the first year of teaching and the developed mechanism to cope with these sources of stress.

\subsection{Lack of Support from Other Teachers and Administrations}

This first year teacher expressed specific frustration regarding the perceived lack of support from other teachers and the administration. She described feelings of being overwhelmed and stressed at times; "right now I would prefer the support, the brainstorming, and the help that is supposed to accompany a first-year teacher" (December 2008). Written in one of her entries she attempted to speak to her department chair about materials and ways to teach her Spanish course. She was confronted with a department chairperson who offered little to no help at all. Her director responded that she had not taught that particular course in approximately fifteen years. Additionally, her department chairperson expressed her displeasure with the textbooks the participant used and recommended that she use other materials. This type of reaction from school administration added to the participant's level of frustration and intensified feelings of stress.

\subsection{Curriculum Challenges and Time Management}

"My biggest frustration to date is...creating lessons from scratch; perhaps I would actually have support; perhaps I would have a life outside of SCHOOL" (December 2008). Finding the proper time and balance between work and family duties, were the next major issues observed. These factors are a few of the challenges that are faced by first time teachers. This first year teacher was taught in her teacher preparation program not to "reinvent the wheel" but to beg, borrow, and steal from her colleagues whenever possible. This would have allowed her to better manage other aspects of her classroom. The major problem identified during this stage in school year, was that this first year teacher was the only individual teaching this particular Spanish course in the entire school and had no one to rely on to obtain any necessary information.

\subsection{Discipline Challenges}

The poorly motivated students posed several discipline challenges for this novice teacher. "I need to improve my classroom management. My 33 students are a vivacious bunch" (March 2009). She tried different "traditional and non-traditional methods" (February 2009), to have all students engaged and minimize interruptions. Classroom management has appeared to be a common issue for first year educators. Despite the amount of time spent in a teacher preparation program or in a student teaching internship, novice teachers lack proper classroom management skills. Behnke et al. (1981), suggested that the use of "direct command, was by far the most common technique" developed by new teachers as a coping mechanism for discipline issues.

\section{Discussion}

This study analyzed the challenges and the coping mechanisms a teacher developed in order to complete the first teaching year. The findings indicated that as a first year teacher, support needs are very high. Throughout the data and from the previously cited studies, there appears to be an inadequate amount of support from surrounding teachers and administrators, which leads to a higher level of stress and frustrations (Ko et al., 2000, p. 186). Other sources that led this first year teacher to feelings of stress were curriculum challenges, time management/balance between personal and work demands, overload of responsibilities and discipline challenges. We observed that with each challenge faced, two common coping mechanisms were set into place to "get by".

First, for this teacher as in many new teachers, the perception that one is overworked and having a high sense of responsibility attributed to feelings of anxiety and stress (Ko et al., 2000). We observed her constant search for "alternate sources of guidance and assistance due to the absence of a qualified mentor" as a means of coping with the frustration in curriculum development (Fantilli \& McDougal, 2005). With the participant in this study, we observed the constant "reaching out" to immediate co-workers and superiors for guidance and feedback. When she was not able to receive the help she was asking for, she reached out to teachers outside of her school. "It is ok to ask for help from someone outside of your department of school" (June 2009). This need of going 
through various sources is a technique that is developed by many first year teachers when they are feeling stressed as well as experiencing high levels of anxiety.

Another form of a coping mechanism that the participant developed throughout her first year as a teacher was the constant re-evaluation of her teachings in order to prevent future reoccurrences (Ko et al., 2000). Her recognition on how she would "tweak some of these routines" (April 2009); specifically referring to the routines she applied in the first teaching year to implement in the following year is a form of self-evaluation. The evaluations were a response mechanism and a way to cope with the lack of support and the discipline challenges she experienced during the first school year. Often first year teachers expressed sentiments of self-doubt and insecurity leading to the constant re-evaluation of current practices in the classroom (Fantilli \& McDougall, 2009).

Ultimately, when this first year teacher received the support she had desperately been requesting, we noted several aspects, specifically her emotions towards teaching overall; a change of direction. She no longer felt as overworked and frustrated as this other teacher bent over backwards to support me and immediately sent me a disc with all of her documents and files so that I would have something from which to plan, design, and teach. Hooray! I started going home around 4:30 instead of 7PM! (June 2009).

Having the guidance from another teacher on how to plan and use the curriculum to its fullest potential eased her responsibility in planning and preparation. The guidance she received in lesson planning now allowed her to invest additional time into addressing the discipline issues at hand. Again, we noted a major change in her stress level and feelings towards teaching change. She appeared satisfied with her role as a teacher.

It appeared that as she progressively faced each challenge, a trickle down effect occurred. When she focused on one challenge and resolved it, it gave way for another challenge to be faced and solved. Eventually leading to the resolution of a common first year teacher issue, properly balancing her time between work and family duties teachers face (Ko et al., 2000). However, this teacher would not have arrived to this stage in her career if that support system she and another teacher developed were not in place.

\section{Implications for Teachers}

Although experts agree and support that having some degree of mentoring or some type of induction program for new teachers, can reduce attrition rates and increase teacher effectiveness (Moir, 2009). The need to establish common standards for all schools when offering and implementing support services such as induction programs to novice teachers, is crucial in the reduction of great variations in mentoring and/or induction programs and in the development of coping mechanisms as a result of the developed feelings of stress (Smith \& Ingersoll, 2004). It is difficult to determine from the studies cited in the literature review the degree of creating teacher effectiveness from these types of programs, since there are vast differences among the structures that each school chooses to implement.

What can be determined from the cited studies is that having just any type of mentoring and/or induction programs is not enough to turn a novice teacher into a "good" teacher. It is imperative that mentoring and induction programs are "organized to accelerate new teacher development" (Moir, 2009). Teachers go through a process of teacher development. It takes a few years before teachers reach a level of effectiveness that will promote student motivation and achievement (Fantilli \& McDougall, 2005). Through the execution of effective induction programs in which a teacher development process can be facilitated may perhaps reduce the number of teachers that exist the field before reaching this level of effectiveness (Fantilli \& Mcdougall, 2005).

An effective induction program assigns mentees with mentors who are on the same grade level in elementary schools or teach the same subject in the middle and secondary grades (Moir, 2009). Choosing mentors who can empower educators are not just accountable, but should be properly trained through professional development and the "tools to advance a new teacher's practice" is key in increasing teacher effectiveness (Moir, 2009). A well established program does not only assist the first year teacher but it also allows for veteran teachers to reflect on their own teaching styles through the questionings of novice teachers, creating a mentoring dyad between the two (Le Maistre \& Pare, 2008). It is important that a school principal creates an atmosphere that supports new teachers through their collaboration with time to assist new teachers in instruction (Moir, 2009). It is also essential to show new teachers that their efforts as educators are valued and encouraged (Moir, 2009). 


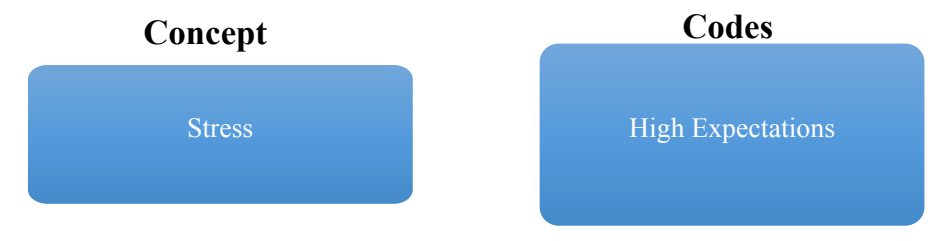

Theory
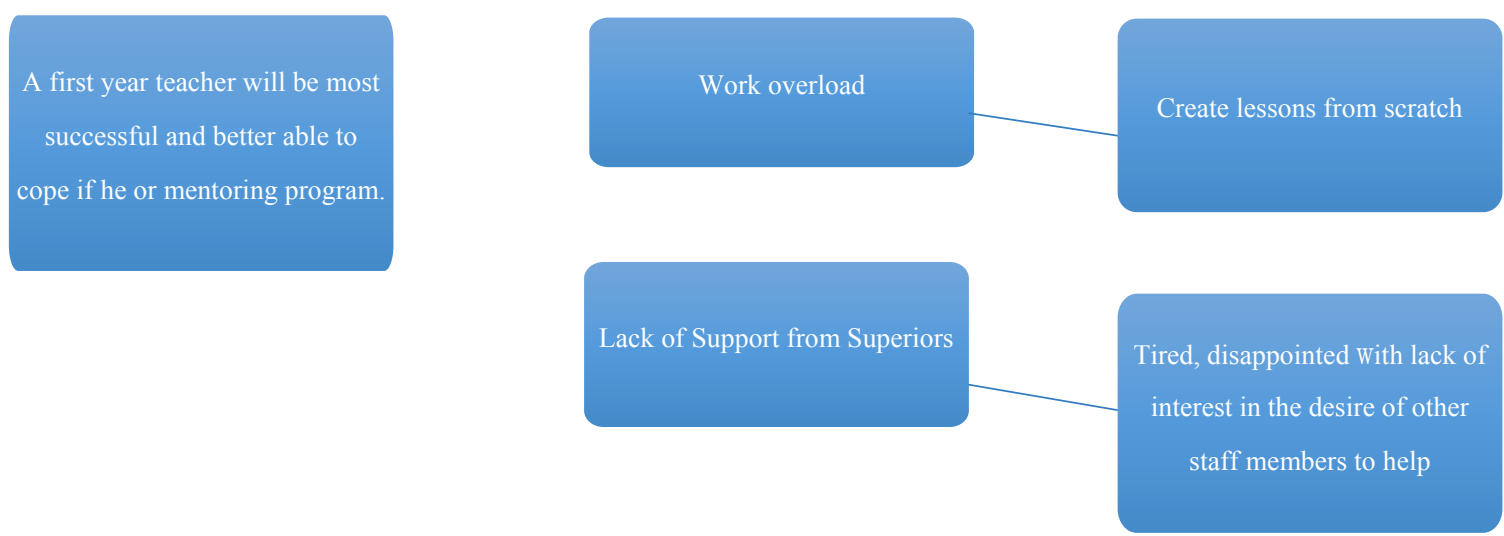

Figure 1. Flow chart models the development and processing involved in generating the study's theory

\section{Limitations}

Due to the limitations of this study, the yielded results from a single female teacher in a high school in Illinois may not be generalized to larger populations.

The limitations from this single subject, who lacked adequate mentorship and/or an induction program, suggests that further studies in the degree of mentorship received is essential in reducing not only attrition rates, but reduce stress related feelings among novice teachers.

Due to the in depth analysis of this participant and from the studies in the literature review, it would be of meaningful value to study novice teachers, to further examine schools that implement similar induction programs to those schools that have their own independent programs, and compare the rate of attrition and levels of stress reported amongst those two categories.

It would also be fundamental to research what the effects are of properly structured induction programs put into practice to assist first year teachers on the academic performances of students in the long run. Little if not, no research has been done concretely and quantitatively to show the relationship between the outcomes of introducing a new teacher into an effective induction program and student performance.

\section{References}

Anita. (2008, August). First year teacher experiences [Web log message]. Retrieved from $\mathrm{http}: / /$ nclrc.org/teachers_corner/teachers_diaries/anita.html

Behnke, G., Labovitz, E. M., Bennett, J., Chase, C., Day, J., Lazar, C., \& Mittleholtz, D. (1981). Coping with classroom distractions. The Elementary School Journal, 81(3), 135-155. https://doi.org/10.1086/461217

Darling-Hammond, L. (2006). Constructing $21^{\text {st }}$ century teacher education. Journal of Teacher Education, 57(3), 300-314. https://doi.org/10.1177/0022487105285962

Darling-Hammond, L. (2010). The at world and education: How America's commitment to equity will determine our future. New York, NY: Teachers College Press.

Darling-Hammond, L., Furger, R., Shields, P. M., \& Sutcher, L. (2016). Addressing California's emerging teacher shortage: An analysis of sources and solutions. Palo Alto, CA: Learning Policy Institute.

Everhart, B., \& Hogarty, K. (2009). Supporting the preparation of beginning teachers with online assessment products. Education, 400-412. Retrieved from http://web.ebscohost.com

Fantilli, R. D., \& McDougall, D. E. (2005). A study of novice teachers: Challenges and supports in the first years. Teaching and Teacher Education, 814-825. Retrieved from http://www.sciencedirect.com 
Goldrick, L. (2016). Support from the Start: A 50-State Review of Policies on New Educator Induction and Mentoring. $\quad$ Retrieved April $\quad 7, \quad 2016, \quad$ from http://newteachercenter.org/wp-content/uploads/2016CompleteReportStatePolicies.pdf

Hale, L. (2015). Behind the shortage of special ed teachers: Long hours, crushing paperwork. NPR. Retrieved from http://www.npr.org/sections/ed/2015/11/09/436588372/behind-the-shortage-of-special-ed-teachers-long-ho urs-crushing-paperwork

Hamlin, K., \& Hering, K. (1988). Help for the first-year teacher: Mentor, buddy, or both? NASSP Bulletin, 72(509), 125-127. https://doi.org/10.1177/019263658807250921

Ko, Y. C., Chan, K. B., Lai, G., \& Boey, K. W. (2000). Stress and coping of Singapore teachers: A quantitative and qualitative analysis. Social Science and Medicine, 181-200. https://doi.org/10.1163/156852200512049

Le Maistre, C., \& Pare, A. (2008). Whatever it takes: How beginning teachers learn to survive. Teaching and Teacher Education, 559-564. Retrieved from http://www.sciencedirect.com

Moir, E. (2009). Accelerating teacher effectiveness: Lessons learned from two decades of new teacher induction. Phi Delta Kappan, 91(2), 15-21. https://doi.org/10.1177/003172170909100204

Nix, N. (2015, December 1). Why Oklahoma is racing to put nearly 1,000 uncertified teachers in its classrooms. The Seventy Four. Retrieved from https://www.the74million.org/article/why-oklahoma-is-racing-to-put-nearly-1000-uncertied-teachers-in-itsclassrooms

Smith, T., \& Ingersoll, R. (2004). What are the effects of induction and mentoring on beginning teacher turnover? American Educational Research Journal, 41(3), 681-714. https://doi.org/10.3102/00028312041003681

Sun, C. (2012). Teacher Induction: Improving State Systems for Supporting New Teachers. Arlington: National Association of School Boards of Education, 3, 2-19. Retrieved from http://www.nasbe.org/wp-content/uploads/DG_Teacher_Induction_March_2012.pdf

Wang, J., Odell, S., \& Schwille, S. (2008). Effects of teacher induction on beginning teachers' teaching. Journal of Teacher Education, 59(2), 132-152. https://doi.org/10.1177/0022487107314002

\section{Copyrights}

Copyright for this article is retained by the author(s), with first publication rights granted to the journal.

This is an open-access article distributed under the terms and conditions of the Creative Commons Attribution license (http://creativecommons.org/licenses/by/4.0/). 